\title{
Review
}

\section{Alzheimer's Disease Can Be Spared by Nonsteroidal Anti-Inflammatory Drugs}

\author{
Patrick L. McGeer*, Jian Ping Guo, Moonhee Lee, Krista Kennedy and Edith G. McGeer \\ Aurin Biotech Inc. Ltd., Vancouver, BC, Canada
}

Accepted 17 August 2017

\begin{abstract}
Alzheimer's disease (AD) is characterized by deposits of amyloid- $\beta$ protein $(A \beta)$ in brain which become foci of inflammation. Neurons are destroyed by this inflammatory process, leading to the cognitive deficits which define AD clinical onset. Epidemiological studies indicate that nonsteroidal anti-inflammatory drugs (NSAIDs) can ameliorate this destructive process if they are started well before clinical signs develop. Biomarker studies indicate that the disease process starts at least a decade before cognitive deficits appear. This pre-clinical onset explains the NSAID effect. It also opens a window of opportunity for preventive treatment that can be met with a simple diagnostic test. Salivary levels of $A \beta_{42}$ may fulfill that need. They can be measured by a simple ELISA test we have developed using commercially available reagents. By this ELISA test, normal controls, who are not at risk for $\mathrm{AD}$, have levels of $\mathrm{A} \beta_{42}$ close to $20 \mathrm{pg} / \mathrm{ml}$. AD cases, as well as high level controls, secrete levels in the range of $40-85 \mathrm{pg} / \mathrm{ml}$. Widespread application of this test to detect high level controls, followed by NSAID consumption, could substantially reduce the prevalence of AD.
\end{abstract}

Keywords: $A \beta_{42}$, epidemiology, neuroinflammation, pre-clinical Alzheimer's disease, saliva

\section{HISTORICAL BACKGROUND}

The modern era of brain research was initiated by investigations into the causes of Alzheimer's disease (AD). We reported in 1988 that AD brains showed activated microglia expressing HLA-DR, an immunology marker previously thought to be exclusively associated with peripheral leukocytes [1]. The myth of brain immunological privilege was thus demolished. It did not go down without a fight. Our first attempt to publish on the subject was rejected by the editor of one prominent journal who was certain the result must be wrong, but was unable to put a finger as to why. The editor decided that any neuropathologist could do so and rejected the paper on the basis of our not having a neuropathologist as an author. Our grant application to support the research

\footnotetext{
${ }^{*}$ Correspondence to: Dr. Patrick L. McGeer, Aurin Biotech Inc Ltd., 4727 West Second Avenue, Vancouver, BC V6T 1C1, Canada. Tel.: +1 604822 7377; Fax: +1 604822 7086; E-mail: mcgeerpl@mail.ubc.ca.
}

was rejected when a peer reviewer evaluated it as a "crazy hypothesis".

As with all breakthroughs, it caused a paradigm shift in thinking. Once that shift took hold, progress became rapid. The result is that today neuroinflammation is the largest field of brain research. Departments of neuroinflammation have now become established in academic institutions to meet the demand.

Epidemiological data soon backed up our immunohistochemical results. In this field, there was less controversy since new methodology was not involved. In 1990, we wrote a short report for Lancet [2] indicating a substantial sparing of $\mathrm{AD}$ in patients with rheumatoid arthritis. We suggested that anti-inflammatory therapy might be the explanation. We chose rheumatoid arthritis for the study since it typically commences at an earlier age than $\mathrm{AD}$, and is universally treated with anti-inflammatory agents.

Our report of $\mathrm{AD}$ sparing in patients consuming anti-inflammatory agents was soon confirmed 
in 17 epidemiological studies [3]. They included incident, prevalent, and case-control studies of patients consuming nonsteroidal anti-inflammatory drugs (NSAIDs) compared with controls. There was one consistent caveat in these epidemiological studies. The NSAIDs needed to have been started at least 6 months, and preferably as long as 5 years, before the clinical diagnosis of AD.

\section{DEVELOPMENTAL YEARS}

A new field of research had been opened up with these epidemiological studies. It required that some important questions be answered. Why was it necessary to commence taking NSAIDs so long before the clinical onset of $\mathrm{AD}$ ? What was the appropriate NSAID dose? And was it necessary to take NSAIDs on a continuing basis?

New techniques were required to provide answers to these questions. We emphasize here the two most important of these: positron emission tomography revealing that deposits of amyloid- $\beta$ protein $(A \beta)$ build up in the brain of $\mathrm{AD}$ cases; and cerebrospinal fluid (CSF) $A \beta$ levels revealing their consequent reduction. These two techniques are complementary. Since the brain $A \beta$ deposits accumulate over time, the effect is integral. Since CSF turns over every few hours, the effect is differential.

Disease development, as revealed by biomarker studies, follows this sequence of events. It commences with $\mathrm{A} \beta$ deposits developing in the brain of AD cases. These deposits can be detected by positron emission tomography (PET) using the $\mathrm{A} \beta$ binding agent Pittsburgh Compound B. The depositions result in a concomitant decrease of $A \beta$ in the CSF. Years later, less definitive biomarkers such as MRI and regional metabolic rate by fluorodeoxyglucose (FDG)-PET become positive. These later biomarkers reveal loss of brain tissue. When they become positive, cognitive deficits have already appeared. Together, these studies indicate that AD onset commences more than a decade before clinical signs develop [4-7]. The ability to identify the onset of $\mathrm{AD}$ a decade or more before clinical signs appear creates a window of opportunity to intervene in the process. Moreover, it explains the epidemiological data in which NSAIDs must be commenced years before clinical detection.

The missing link is a simple, non-invasive method for identifying those at risk at an age well below the typical age of $\mathrm{AD}$ onset.

\section{PROVIDING THE MISSING LINK}

Analysis of saliva for $A \beta_{42}$ may provide the missing link. However, the data we present is preliminary and will need to be confirmed by further studies. We first developed a simple ELISA method for determining $A \beta_{42}$ levels in tissues as well as saliva [8]. The results showed that $A \beta_{42}$ is produced in all tissues of the body, and not just in brain as many have believed.

$A \beta_{42}$ secretion in saliva is a reflection of its production by submandibular glands. The results are shown in Table 2 for a series of AD and non-AD cases. The non-AD cases resolved into two distinct categories: those with low levels in the $19-25 \mathrm{pg} / \mathrm{ml}$ range, and those with high levels in the AD range of 41-60 $\mathrm{pg} / \mathrm{ml}$. Significantly, there were no overlapping cases.

Analysis of $A \beta_{42}$ levels in saliva demonstrates three remarkable facts. Firstly, controls, who are not at risk for $\mathrm{AD}$, secrete levels close to $20 \mathrm{pg} / \mathrm{ml}$, regardless of sex or age (see Table 1). Secondly, this production is constant, being invariant with time of day, and from day to day. Thirdly as Table 2 shows, those at risk for $\mathrm{AD}$ secrete levels comparable to $\mathrm{AD}$ cases [8].

The demonstration of a constant activity of genes, and their expression everywhere in the body, requires a paradigm shift in our concept of how many genes function. They are expressed in every tissue at a constant rate around the clock, with no variation throughout life. We are currently investigating whether NSAID consumption can affect these levels.

A theoretical construct suggests the development of AD goes through 6 phases, each with decreasing opportunity for therapeutic intervention [9]. Since the prevalence of clinical AD commences at age 65, the prevalence for actual AD disease onset can be hypothesized to occur at least 10 years earlier, or at age 55. Without intervention, the prevalence will then

Table 1

$\mathrm{A} \beta_{42}$ levels in human organs measured by our ELISA method

\begin{tabular}{lr}
\hline Human tissue & $\begin{array}{r}\mathrm{A} \beta_{42} \text { levels } \\
(\mathrm{pg} / \mathrm{ml})\end{array}$ \\
\hline Lung & 83.68 \\
Heart & 88.59 \\
Kidney & 122.65 \\
Hippocampus & 102.45 \\
Sensory Cortex & 97.83 \\
Liver & 90.56 \\
Spleen & 134.38 \\
Small intestine & 80.58 \\
Pancreas & 128.22 \\
\hline
\end{tabular}


Table 2

$\mathrm{A} \beta_{42}$ levels in normal and AD cases measured by our ELISA method

\begin{tabular}{|c|c|c|c|c|c|c|c|c|c|c|c|}
\hline \multicolumn{4}{|c|}{ Normal (Low controls) } & \multicolumn{4}{|c|}{$\mathrm{AD}$} & \multicolumn{4}{|c|}{ Normal (High Controls) } \\
\hline Case & Age & Gender & $\mathrm{A} \beta_{42}(\mathrm{pg} / \mathrm{ml})$ & Case & Age & Gender & $\mathrm{A} \beta_{42}(\mathrm{pg} / \mathrm{ml})$ & Case & Age & Gender & $\mathrm{A} \beta_{42}(\mathrm{pg} / \mathrm{ml})$ \\
\hline 1 & 46 & Male & 25.32 & 1 & 52 & Female & 59.57 & 1 & 71 & Female & 48.31 \\
\hline 2 & 53 & Male & 24.44 & 2 & 60 & Female & 47.96 & 2 & 79 & Male & 45.28 \\
\hline 3 & 89 & Male & 22.35 & 3 & 57 & Male & 41.58 & 3 & 52 & Female & 59.57 \\
\hline 4 & 16 & Male & 21.47 & 4 & 72 & Female & 41.69 & 4 & 70 & Female & 41.12 \\
\hline 5 & 19 & Male & 20.27 & 5 & 77 & Female & 84.97 & 5 & 71 & Male & 39.66 \\
\hline 6 & 19 & Female & 19.73 & 6 & 78 & Male & 48.89 & 6 & 71 & Male & 41.83 \\
\hline 7 & 22 & Male & 22.27 & 7 & 84 & Female & 64.93 & & & & \\
\hline 8 & 24 & Male & 21.53 & 8 & 86 & Female & 75.20 & & & & \\
\hline 9 & 39 & Male & 22.22 & 9 & 91 & Male & 56.67 & & & & \\
\hline 10 & 42 & Male & 20.58 & 10 & 84 & Male & 49.94 & & & & \\
\hline 11 & 47 & Female & 20.15 & 11 & 78 & Female & 55.93 & & & & \\
\hline 12 & 54 & Male & 20.05 & 12 & 75 & Female & 47.93 & & & & \\
\hline 13 & 54 & Female & 20.56 & 13 & 75 & Female & 60.68 & & & & \\
\hline 14 & 55 & Female & 29.66 & 14 & 74 & Male & 63.73 & & & & \\
\hline 15 & 54 & Male & 22.32 & 15 & 8 & Male & 42.77 & & & & \\
\hline 16 & 57 & Female & 19.61 & 16 & 72 & Female & 45.95 & & & & \\
\hline 17 & 57 & Female & 23.07 & 17 & 64 & Female & 53.83 & & & & \\
\hline 18 & 59 & Male & 21.55 & 18 & 48 & Female & 49.26 & & & & \\
\hline 19 & 60 & Male & 22.02 & 19 & 78 & Female & 58.28 & & & & \\
\hline 20 & 62 & Male & 21.37 & 20 & 83 & Male & 44.19 & & & & \\
\hline 21 & 78 & Male & 21.44 & 21 & 80 & Female & 51.11 & & & & \\
\hline 22 & 83 & Female & 20.56 & 22 & 79 & Male & 49.07 & & & & \\
\hline 23 & 86 & Male & 21.37 & 23 & 84 & Female & 46.62 & & & & \\
\hline 24 & 88 & Male & 22.46 & & & & & & & & \\
\hline 25 & 92 & Female & 20.89 & & & & & & & & \\
\hline
\end{tabular}

Values are Mean \pm SEMs; Normal (Low controls): $21.54 \pm 0.19$, AD: $53.95 \pm 2.24$, and Normal (High controls): 45.96 \pm 3.01 , respectively. One-way ANOVA was carried out to test significance. $p<0.001$ for AD and Normal (High controls) cases compared with Normal (Low controls).

double every five years. It is characterized by the start of $A \beta$ deposition in brain with consequent decreases in the CSF. Therapeutic opportunities at this initial stage are at their highest. Any strategy which limits $A \beta$ production, enhances its clearance, or prevents its aggregation, should be disease modifying. Effectiveness of treatment should be measurable by CSF A $\beta$ levels returning toward normal.

Biomarker studies suggest that phase 2 sets in about 5 years later. $A \beta$ deposits in the brain have built up to the level where they can be easily detected by PET scanning with Pittsburgh compound B. A $\beta$ decreases in the CSF continue. They are now joined by tau levels. Therapeutic opportunities have declined because cortical tau aggregation in brain has been induced. Ideally, a tau aggregation inhibitor should now be added to any therapeutic regimen, but so far none have been produced. Given that tau aggregation is the central pathogenic event in more than two dozen neurodegenerative diseases, developing such an agent is an urgent priority.

In phase 3 , typically after another 5 years, there is a slight metabolic decline that can be demonstrated by a reduction in FDG uptake by PET scanning.
Presumably this is due to synaptic loss. Cortical tangle and thread development have occurred. $A \beta$ and tau continue to be expressed at the same levels in the CSF. Pittsburgh compound B scanning intensity has increased. Therapeutic opportunities have further declined.

Phase 4, in another 5 years, represents disease progression to the level where mild cognitive impairment is detectable. Hippocampal atrophy becomes evident by MRI scanning. The disease can no longer be totally prevented. Irreversible brain damage has begun to occur. $A \beta$ and tau continue to be expressed at the same levels in the CSF.

Phase 5, in another 5 years, represents the level where AD can easily be diagnosed clinically. Neuronal damage and loss is evidenced by further PET-FDG metabolic decline and increasing brain volume loss by MRI. A $\beta$ deposits in brain continue to accumulate. Opportunities for therapeutic intervention have seriously declined.

Phase 6 defines the period of progressive clinical decline in all aspects of the disease. Cognitive deficits progress from mild to severe. Full-time care of patients becomes necessary. Costs associated with 
their care escalate. Therapeutic opportunities are minimal and yet it is in this phase that most clinical trials have been conducted. The result has been a failure in 242 of the last $243 \mathrm{AD}$ clinical trials. The one exception was for memantine, a me-too agent affecting acetylcholine production rather than $\mathrm{AD}$ itself. The situation fits Albert Einstein's definition of investigator insanity. That is to do the same experiment over and over hoping for a different answer.

To be a truly successful disease-modifying agent, a therapeutic candidate needs to deter $A \beta_{42}$ aggregation, or intervene in its consequences, prior to the time when tau aggregation takes hold. For example, early application of direct inhibitors of $A \beta$ aggregation, or inhibitors of $\beta$-secretase, or $\gamma$-secretase might succeed. Active immunization is highly questionable, given the dangers of inducing an autoimmune disorder and stimulating self-attack by complement. Passive immunization is also unlikely to succeed, due to the problems of blood-brain barrier penetration. Repeated failures of such agents have already been demonstrated.

\section{DISCLOSURE STATEMENT}

Authors' disclosures available online (http://j-alz. com/manuscript-disclosures/17-0706r1).

\section{REFERENCES}

[1] McGeer PL, Itagaki S, Tago H, McGeer EG (1987) Reactive microglia in patients with senile dementia of the Alzheimer type are positive for the histocompatibility glycoprotein HLA-DR. Neurosci Lett 79, 195-200.
[2] McGeer PL, McGeer EG, Rogers J, Sibley J (1990) Antiinflammatory drugs and Alzheimer disease. Lancet 335, 107.

[3] McGeer PL, Schulzer M, McGeer EG (1996) Arthritis and antiinflammatory agents as negative risk factors for Alzheimer disease: A review of seventeen epidemiological studies. Neurology 47, 425-432.

[4] Bateman RJ, Xiong C, Benzinger TL, Fagan AM, Goate A, Fox NC, Marcus DS, Cairns NJ, Xie X, Blazey TM, Holtzman DM, Santacruz A, Buckles V, Oliver A, MoulderK, Aisen PS, Ghetti B, Klunk WE, McDade E, Martins RN, Masters CL, Mayeux R, Ringman JM, Rossor MN, Schofield PR, Sperling RA, Salloway S, Morris JC. Dominantly Inherited Alzheimer Network (2012) Clinical and biomarker changes in dominantly inherited Alzheimer's disease. New Engl J Med 367, 793-804.

[5] Villemagne VL, Burnham S, Bourgeat P, Brown B, EllisKA, Salvado O, Szoeke C, Macaulay SL, Martins R, MaruffP, Ames D, Rowe CC, Masters CL, Australian Imaging Biomarkers, Lifestyle (AIBL) Research Group (2013) Amyloid deposition, neurodegeneration, and cognitive decline in sporadic Alzheimer's disease: A prospective cohort study. Lancet Neurol 12, 357-367.

[6] Prestia A, Caroll A, van der Flier WM, Ossenkoppele R, Van Berckel B, Barkhof F, Teunissen CE, Wall AE, Carter SF, Schöll M, Choo IH, Nordberg A, Scheltens P, Frisoni GB (2013) Prediction of dementia in MCI patients based on core diagnostic markers for Alzheimer disease. Neurology 80, 1048-1056.

[7] Buchhave P, Minthon L, Zetterberg H, Wallin AK, Blennow $\mathrm{K}$, Hansson O (2012) Cerebrospinal fluid levels of $\beta$-amyloid $1-42$, but not of tau, are fully changed already 5 to 10 years before the onset of Alzheimer dementia. Arch Gen Psychiatry 69, 98-106.

[8] Lee M, Guo JP, Kennedy K, McGeer EG, McGeer PL (2017) A method for diagnosing Alzheimer's disease based on salivary amyloid- $\beta$ protein 42 levels. J Alzheimers Dis 55, 1175-1182.

[9] McGeer PL, McGeer EG (2013) The amyloid cascade inflammatory hypothesis of Alzheimer disease. Acta Neuropathol 126, 479-497. 